\title{
Analysis of pressure difference changes in respirator filters while dusting
}

\author{
Serhii Cheberiachko ${ }^{1 *}$, Olena Yavorska $^{1}$, Yurii Cheberiachko ${ }^{1}$, and Andrii Yavorskyi ${ }^{2}$ \\ ${ }^{1}$ National Mining University, Department of Aerology and Labour Protection, 19 Yavornytskoho \\ Ave., 49005 Dnipro, Ukraine \\ ${ }^{2}$ National Mining University, Department of Underground Mining, 19 Yavornytskoho Ave., \\ 49005 Dnipro, Ukraine
}

\begin{abstract}
Objective is to determine the relation between pressure difference of a filter and parameters of a filtering layer to lengthen the protection period. The study involved elements of system analysis and mathematical modeling. Basic statements of the theory of nonstationary filtration and aerohydrodynamics were applied to develop a dust-loaded filter model. Dependence of pressure difference in a filter upon certain changes in packaging density of dust-loaded fibers has been determined; the dependence makes it possible to define minimum fiber packaging density to provide maximum dust capacity. To provide maximum dust capacity and high protective efficiency, the number of filtering layers in multilayered filters depends upon dust concentration within the air of the working zone, specified protection level of a respirator, air loss, and maximum dust volume which may be accumulated in the finishing filtering layer in terms of fiber packaging density being determined according to the minimum pressure difference in a filter at final time of respirator operation. A model of changes in pressure difference in filtering respirators in the process of aerosol particles depositing on filters has been improved; contrary to other available models, that one takes into consideration changes in fiber packaging density while dusting, filtration coefficient, and the amount of aerosol particles.
\end{abstract}

\section{Introduction}

Coal dust does not only contaminate atmospheric air and environment [1], it is also dangerous for those peoples working immediately at mining enterprises. Efficiency of mining enterprises is based upon sustainable development of economic constituents of mineral extraction during both underground [2 -5] and open-cast [6] mining with the provision of environmental issues of the process. Today's world practice demonstrates the tendency of broad-scale implementation of clean coal technologies being formed at the territory of mining enterprises. The technological solutions are the basis for the operation of energy and chemical complexes for coal gasification [7, 8]. Gasification process takes place within a closed system: underground generator - ground complex that practically restricts the emission of harmful generator gases into the environment [9]. However, it is impossible

\footnotetext{
*Corresponding author: sicheb@ukr.net
} 
to eliminate completely negative effect of dust upon people. Thus, use of dust respirator under such conditions is the only way to protect respiratory organs of miners.

To provide high-efficiency dust protection, it is required to use low breathing resistance respirators which are characterized by minor effect upon functional state of workers. Otherwise, they will not be used during the whole shift [15]. Thus, the studies aimed at the improvement of ergonomic parameters of respiratory protective devices are of special topicality $[10,11,16]$.

\section{Statement of the problem}

There are following basic structural, functional, and operational characteristics of filters [11]: protection coefficient $-K_{z}$; initial pressure difference $-\Delta p$; protection period $-t_{k}$; filtration area $-F$; shape and size of a filter $-H_{f}$, length $-L_{f}$; properties of a filtering layer which effect penetration coefficient: fiber radius $-a$, fiber packaging density $-\beta$; thickness of a filtering layer $-H$; and airflow resistance $-R_{0}$.

The first three characteristics are selected basing upon the purpose and conditions of filter application. The last three ones are determined on the basis of the preset conditions. There are numerous variants which can meet the initial data. Their functional relations are defined by following system of equations $[13,17]$ :

$$
\begin{gathered}
K_{z}=\frac{100}{\exp \left(-\frac{2 \cdot \beta \cdot H \cdot \eta(a)}{\pi a}\right)}, \\
E=1-\exp \left(-\frac{2 \cdot \beta \cdot H \cdot \eta(a)}{\pi a}\right), \\
\Delta p_{f}=\mu \cdot v \cdot R_{0} \cdot L
\end{gathered}
$$

where $\eta(a)$ is total coefficient of aerosol particles catching; $\mu$ is dynamic air viscosity, $\mathrm{Pa} \cdot \mathrm{s} ; v$ is filtering rate, $\mathrm{m} / \mathrm{s} ; R_{0}$ is non-dimensional force of fiber airflow resistance; $L$ is total length of fibers in a filter, $\mathrm{m}^{-1}$ :

$$
L=\frac{\beta H}{\pi a^{2}} .
$$

However, to determine filtering layer parameters. It is necessary to define their effect upon pressure difference on a filter upon its dusting time; that will make it possible to predict the protection period. The latter is limited by the boundary admissible pressure difference that is determined by the corresponding normative documents. For instance, according to EN149:2003, in terms of filtering half-masks it should be not more than $400 \mathrm{~Pa}$ for class P1; not more than $500 \mathrm{~Pa}$ for class P2, and not more than $700 \mathrm{~Pa}$ for class $\mathrm{P} 3$, if air loss in $95 \mathrm{l} / \mathrm{min}$. Determination of the mentioned relation is of special importance to calculate the parameters of multilayered filters when there is the necessity in defining packaging density of previous filtering layers. 


\section{Theoretical studies}

It is required to determine changes in pressure differences during dust deposit accumulation on fibers within time $t$ in terms of filtering layer thickness $(x)$ at known parameters of filtering material (radius of fibers, density of filtering layer thickness packaging), and the preset conditions of a filtering process (airflow rate, particles concentration, and their average radius).

Use two cross sections to highlight elementary filtering layer with width $\Delta x$ at the distance $x$ from the filter surface. Suppose that the area of cross section is equal to a unit. Air with the dust amount $n_{1}$ goes to section 1-1; dust amount $n_{2}$ goes out through section 2-2 (Fig. 1).

Decrease in the amount of particles in the elementary filtering layer is:

$$
\Delta n=-\left(n_{2}-n_{1}\right)=-\frac{\partial n}{\partial x} \Delta x
$$

Derivative $\frac{\partial n}{\partial x}$ demonstrates certain change in the amount of deposited aerosol particles per unit of filtering layer thickness. The value is expressed by means of a derivative since the amount of particles in each section depends upon two derivatives: $x$ - upon the distance from filter surface and $t$ - from filtering time. The sign of minus in equation (1) shows that the amount of particles within the flow decreases along with the increase in filtering layer thickness.

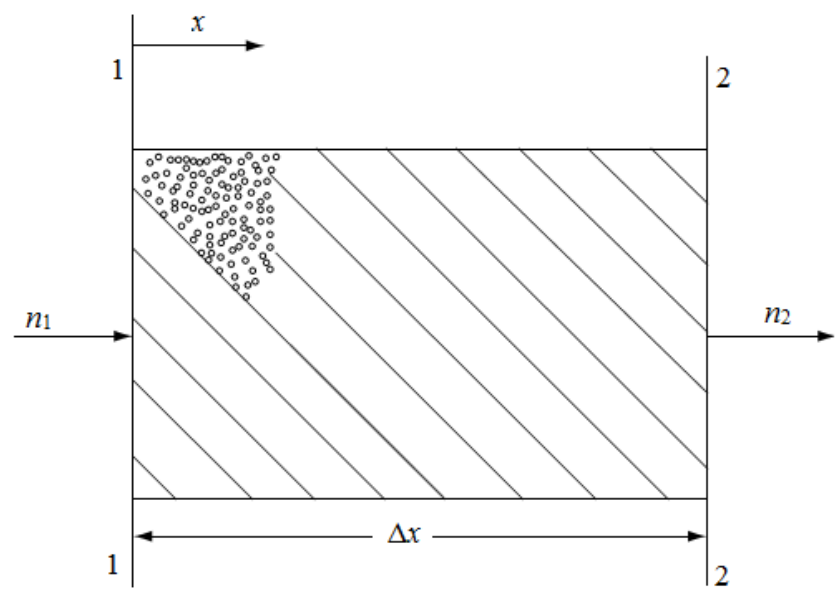

Fig. 1. Scheme of dust deposit accumulation on a filter during volumetric filtration.

Certain amount of air with rate $v$ goes through a unit of cross section area of the highlighted layer. Respectively, the amount of substance caught on a filtering layer per time $t$ is:

$$
\Delta G=v(t) \Delta n=-v(t) \frac{\partial n}{\partial x} \Delta x .
$$

Particles caught by a filtering layer form deposit on filtering fibers that is accumulated while filtering being the reason of further increase in filter density. Its growth in thickness $\Delta x$ per time moment $t$ will be $\Delta x$ while the rate of accumulations deposited in a filtering 
layer per time unit is:

$$
\Delta G=\frac{\partial \beta_{1}}{\partial t} \Delta x
$$

where $\beta_{1}$ is the density of deposit packaging in a filtering layer related to a volume unit of the elementary filtering layer.

While equalizing expressions (2) and (3), we obtain:

$$
\frac{\partial \beta_{1}(x, t)}{\partial t}=-v(t) \frac{\partial n(x, t)}{\partial x} .
$$

That differential equation is a well-known mass balance equation. It shows that the amount of the substance passing through a filtering layer per time unit is equal to the amount of the deposited substance in that layer per similar period of time. Equation (4) includes two dependent values: $n(x, t)$ and $\beta_{1}(x, t)$. Thus, to describe the process, we need other equation demonstrating specificity of a filtering process.

Consider the process of particles deposition on an obstacle as a total result of two contrary processes: particles catching by means of their sticking to filter fibers and tearing off the stuck particles while exhaling. In that case, decrease in the amount of the accumulated particles within the area $\Delta x$ may be determined according to formula

$$
\Delta n=\Delta n_{1}-\Delta n_{2},
$$

where $\Delta n_{1}$ is the reduction in the particles amount at the expense of their sticking; $\Delta n_{2}$ is the increase of the particles amount at the expense of their tearing off.

Decrease in the particles amount due to their sticking may be taken as the one to be proportional to average amount of particles within the airflow passing through a filter as Ivasaki proposed

$$
\Delta n_{1}=\gamma n \Delta x .
$$

Assume the increase in the amount in the air entering a filter as the one to be proportional to the amount of the accumulated deposit before time $t$, then equation (6) may be represented as:

$$
\Delta n_{2}=a_{1} \beta_{1} \Delta x,
$$

where $a_{1}$ is the coefficient depending upon filter parameters, mechanism of particles tearing off, and size of the particles.

Equation (7) expresses the assumption that the rate of particles tearing off follows such a law:

$$
\frac{\partial \beta_{1}}{\partial t}=-a_{1} \beta_{1}
$$

It is quite possible to have a balance equation for the process of dust deposit destruction between filtering layer fibers which will be similar to equation (4).

Having substituted $\Delta n_{1}$ from (2) and $\Delta n_{2}$ from (7) into equation (1), we obtain:

$$
-\frac{\partial n(x, t)}{\partial x}=\gamma(x, t) n(x, t)-a_{1} \beta_{1},
$$

where $\gamma(x, t)$ is the filtration coefficient demonstrating a mechanism of particles deposition 
on fibers.

Basing upon equation (4) and (9), it is possible to determine changes in dust deposit density while filtering:

$$
\frac{\partial \beta_{1}(x, t)}{\partial t}=v(t) \gamma(x, t) n(x, t)-a_{1} \beta_{1} .
$$

The phenomenon of particles tearing off while filtering in elastomeric half-masks may be neglected as the exhale is performed through the exhalation valve; thus, dust deposit structure is not broken:

$$
-\frac{\partial \beta_{1}(x, t)}{\partial t}=v(t) \gamma(x, t) n(x, t) .
$$

If we represent expressions (9) and (4) as a system of equations with the initial conditions $\beta_{1}(x, 0)=\beta ; n(0, t)=n_{0}$, where $\beta$ is the density of clean filter fiber packaging; $n_{0}$ is the initial concentration of aerosol particles within the air mixture $\left(\mathrm{mg} / \mathrm{m}^{3}\right)$, entering a filter, then its solution is as follows:

$$
\begin{aligned}
& n(x, t)=n_{0} \exp \left(-\int_{0}^{H} \gamma(x, t) d x\right) \\
& \beta_{1}(x, t)=\beta+n(x, t) \theta(t) A_{1}(x)
\end{aligned}
$$

where

$$
\theta(t)=\int_{0}^{t} v(t) d t ; A_{1}(x)=\gamma(x, t) \exp \left(-\int_{0}^{H} \gamma(x, t) d x\right) .
$$

To calculate dust-loaded fiber packaging density, it is required to set the change in filtration coefficient in the process of aerosol particles deposition $\gamma(x, t)$.

It is usually represented as linear:

$$
\gamma(x, t) \approx \gamma_{0}+b x t
$$

where $\gamma_{0}$ is the initial filtration coefficient of a clean filter.

Filtration coefficient for a dust-free fibrous filter may be determined according to a known formula:

$$
\gamma_{0}=\frac{2 \cdot \eta(a) \cdot \beta \cdot H}{\pi a^{2}} .
$$

Coefficient $a$ is determined experimentally; it depends upon the mechanisms of aerosol particles catching as well as their size and properties. Paper [14] indicates that its value for dolomite dust particles of 1-5 mcm may be within the range of $0.25-0.5$.

In other cases it is possible to use the formula proposed by L.V. Radushkevych:

$$
b=\frac{k}{r_{c} \cdot n \cdot t},
$$

where $k$ is the coefficient of test-aerosol penetration through a filtering layer; $r_{c}$ is the aerosol particle radius, $m$. 
Fig. 2 represents the curves of distribution of dust particles deposition and dust deposit packaging density in terms of thickness of a filtering polypropylene layer for which $\gamma_{0}=0.5 ; a=2.5 \mathrm{mcm} ; H=4 \mathrm{~mm} ; \beta=0.05$. The amount of dust particles of $5 \mathrm{mcm}$ in diameter was determined upon the condition that their concentration was $100 \mathrm{mg} / \mathrm{m}^{3}$ within the volume of $1 \mathrm{~m}^{3}$. Filtration rate was $0.01 \mathrm{~m} / \mathrm{s}$.

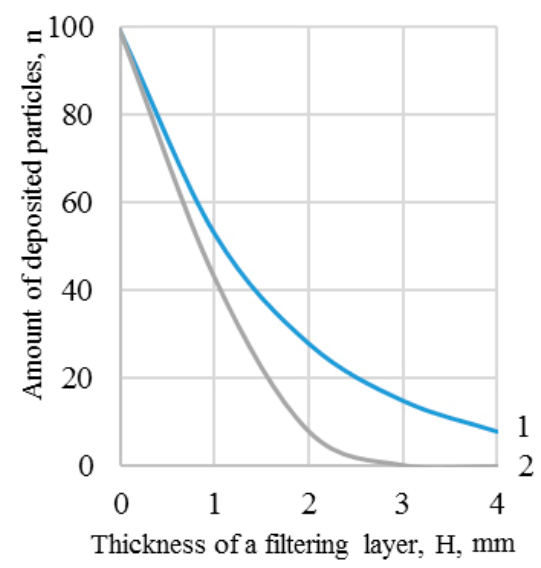

Fig. 2. Distribution of particles amount in a filtering layer in terms of different filtration coefficients: 0.25 (1) and 0.5 (2).

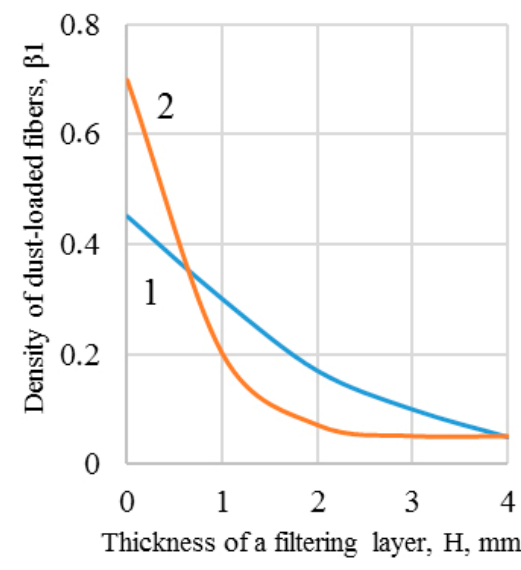

Fig. 3. Distribution of dust-loaded fiber packaging density in a filtering layer in terms of different filtration coefficients: 0.25 (1) and 0.5 (2).

Along with the increase of the filtration coefficient, we can observe that the basic mass of aerosol particles deposits within the upper shares of a filtering layer, hence reducing the period of a volumetric filtration phase. For instance, in case of multilayered filters, it is essential to provide uniform dust saturation for the whole filter thickness. Whereas in case of one-layer filter the efficiency of aerosol particle catching is the first thing to consider. Thus, the first case requires selecting a filter with low filtration coefficient while the second one requires a filter with high filtration coefficient.

If we imagine that particles are accumulated on a filter according to a dendritic model based upon the assumption on the formation of additional chains-dendrites, then they can be represented as fibers with the radius similar to the radius of the deposited particles. In such case, pressure difference of a dust-loaded filter is expressed according to formula:

$$
\begin{gathered}
\Delta p(x, t)=\frac{4 \mu v \beta_{1}}{\pi a^{2}} \int_{0}^{H} F\left[\beta_{1}(x, t)\right] d x= \\
=\frac{2 \mu \nu H \beta_{1}}{\pi a^{2}} \int_{0}^{H}\left[2 \beta+a \beta_{1} \exp \left(n(x, t) \theta(t) A_{1}(x)\right)+3 a^{2} \beta_{1} \exp \left(2 n(x, t) a \theta(t) A_{1}(x)\right)\right] d x .
\end{gathered}
$$

Expression (14) makes it possible to analyze the effect of various parameters upon filter indices (Fig. 4 and 5) and detect the most influential ones.

Fiber density packaging also effects the value of pressure difference and mechanism of deposit distribution in terms of its thickness. The less it is, the deeper particles may penetrate into the middle of a filtering layer and effect the time of reaching critical breathing resistance (Fig. 6 and 7). 


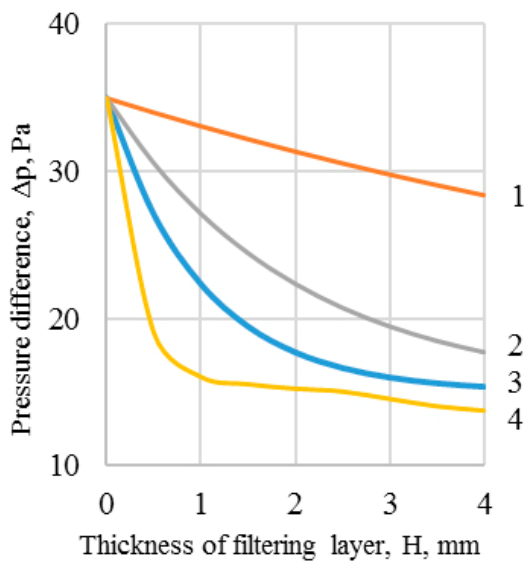

Fig. 4. Curve of changes in pressure difference in terms of different initial fiber packaging density of a filter: 0.5 (1); 0.1 (2); 0.07 (3); 0.05 (1).

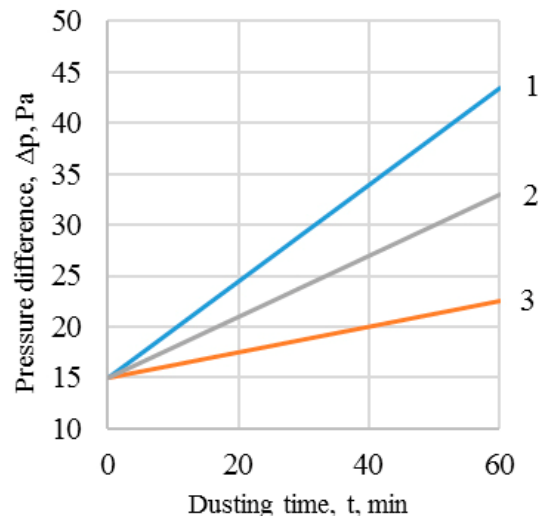

Fig. 6. Change in pressure difference during time in terms of different initial fiber packaging density: 0.05 (1); 0.1 (2); (3); 0.5 (1).

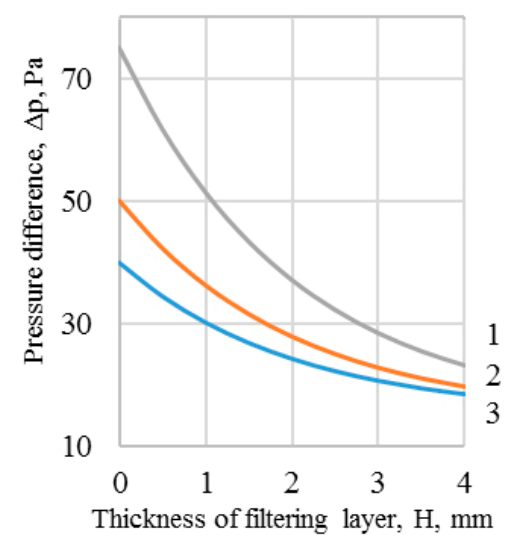

Fig. 5. Curve of changes in pressure difference in terms of filter thickness at different initial concentration of dust particles, $\mathrm{mg} / \mathrm{m}^{3}: 100$ (1); 50 (2); 25 (3).

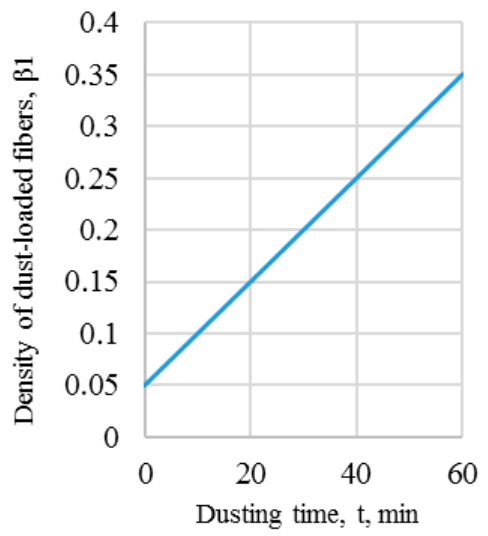

Fig. 7. Change in density of dust-loaded fiber packaging during time in terms of the initial fiber packaging density being 0.05 .

Formula (14) (on the condition of substituting $\beta_{1}$ for $\beta$ and assuming that filtration coefficient depends only upon fiber packaging density $\gamma(x)=B \cdot H \cdot \beta(x)$ allows determining distribution pattern of fiber packaging density in terms of dustless filter as for the thickness to provide maximum accumulated amount of dust per specified time:

$$
\beta(x)=\frac{G}{B \cdot H}\left(1+\tau_{1} n(x, t)\right)^{-\frac{q}{(q+1)}},
$$

where $B=\frac{2 \eta(a)}{\pi a^{2}} ; \quad G=\int_{0}^{H}\left(1+\tau_{1} n(x, t)\right)^{\frac{q}{q+1}} d x$ is the function determining changes in 
aerosol particles concentration in terms of filter thickness; $\tau_{1}=\frac{\theta(t) B}{A_{1}} ; q$ is the coefficient which takes into account changes in fiber packaging density in terms of dust deposit accumulation $(0.5-2.8)$.

Determine minimum fiber packaging density in terms of thickness for polypropylene filtering material, if protection coefficient is at the level of 100 units. Calculation results are represented on Fig. 8 and 9. It can be observed that to expand the protection period it is required to decrease fiber packaging density within the upper share of a filter. In this context, lower layers should be made less dense to provide sufficient protection level.

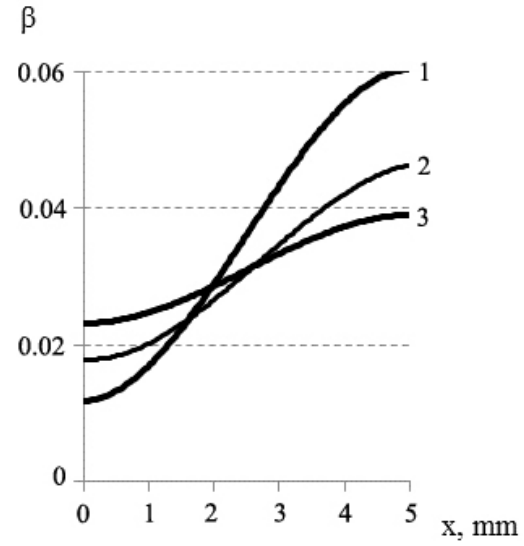

Fig. 8. Distribution of fiber packaging density $(\beta)$ in terms of filtering layer thickness $(x)$ for the final time of dusting $t_{k}=30 \mathrm{~min}$; if $q=0.5$; $\tau_{1}=1.5(1) ; q=0.5 ; \tau_{1}=1(2) ; q=0.5 ; \tau_{1}=$ $0.5(3)$.

Since it is quite a complex task to manufacture filters with changeable packaging density, it is proposed to make them of several various-density layers. The number of the required layers $\left(k_{s}\right)$ will depend upon fiber packaging density of the last layer calculated on the basis of specified efficiency and maximum dust volume which will be accumulated on a filtering layer in terms of minimum pressure difference at final time:

$$
k_{\mathrm{s}}=\frac{C \cdot Q \cdot t_{k}}{\rho_{c} \cdot V_{\max }}
$$

where $V_{\max }=\pi \cdot \beta_{1} \cdot \eta(a) \cdot r_{c}^{3}$ is maximum dust volume which may be accumulated on one filtering layer at minimum pressure difference in a filter at final time; $Q$ is air loss, 1/min; $t_{k}$ is the completion time of volumetric filtration phase, min.

To determine completion time of a volumetric accumulation phase, imagine that generally the character of time changes of various-fraction particles amount on the filter surface is uniform. In this context, the amount of deposited particles on fibers increases monotonously: in the beginning, the growth is quite fast; then it becomes slower being as follows within the specified time: 


$$
n(x)=\frac{1}{k} \cdot \frac{\eta(a)}{a},
$$

while the time of dust deposit accumulation may be determined as:

$$
t_{k}=\frac{2.3}{a \cdot v \cdot n(x)} \lg \left(1-2^{-\frac{1}{k}}\right)^{-1} \text {. }
$$

Process of volumetric filtering of aerosol particles is capable of increasing protective period of filters. It is especially required for multilayered filters. Since it is the time of pore plugging of a previous layer that is the determining one to calculate the parameters of a finishing layer, then the analysis of the obtained dependences makes it possible to state that fiber packaging density has the most considerable effect upon the increase in pressure difference at minor filtration rates being up to $0.01 \mathrm{~m} / \mathrm{s}$ (that is characteristic for respirator filters) while dusting. It is the sharp rise of filter breathing resistance (Fig. 6) in the beginning of its operation that tells about the fact that the main dust mass deposits within the upper layers not penetrating lower due to certain fiber density. Dendritic model proposed to calculate changes in pressure difference provides that, having entered the filter thickness, aerosol particles deposit on clean fibers first. Then they began depositing on each other forming certain branching similar to fibers, i.e. the formed chains increases the density of filter packaging. Thus, there is the necessity to determine distribution of fiber density in terms of filter thickness to provide uniform distribution of dust deposit. It is quite difficult to take into consideration that a filter should also have a specified coefficient of protection. Along with the lengthening of filter operating time, there is a necessity to reduce fiber packaging density; if there is a necessity to provide the required protection efficiency, fiber packaging density should be increased. The solution is right in the production of multilayered filters with different packaging density. To do that, it is recommended to define the amount of layers and to select other filter parameters basing upon the completed volumetric filtration phase that will provide maximum dust accumulation (maximum use of a filtering layer).

\section{Conclusions}

Dependence of pressure difference in a filter upon changes in density of dust-loaded fiber packaging making it possible to define minimum density of fiber packaging to provide maximum dust capability has been determined.

The number of filtering layers in multilayered filters to provide their maximum dust capability and high protective efficiency depends upon dust concentration within the air of a working zone, specified level of respirator protection, air loss, and maximum dust volume that may be accumulated in the finishing filtering layer in terms of fiber packaging determined according to minimum pressure difference in a filter at finite time of respirator operation.

Model of pressure difference changes in filtering respirators in the process of aerosol particles deposition on filters has been improved. Contrary to many other models, that one takes into consideration changes in fiber packaging density, filtration coefficient, and the amount of aerosol particles.

The study is carried out within the framework of the research subject "Scientific basics to form unified system to preserve and generate power of the objects of fuel and energy complex of Ukraine" (State registration No. 0117U001127). 


\section{References}

1. Kolesnik, V.Ye, Pavlichenko, A.V., \& Buchavy, Yu.V. (2016). Determination of dynamic parameters of dust emission from a coal mine fang. Naukovyi Visnyk Natsionalnoho Hirnychoho Universytetu, (2), 81-87.

2. Buzylo, V., Yavorsk'yy, A., \& Yavorsk'yy, V. (2012). Analysis of stress-strain state of rock mass while mining chain pillars by chambers. Geomechanical Processes During Underground Mining, 95-98. https://doi.org/10.1201/b13157-16

3. Buzilo, V., Serdyuk, V., \& Yavorsky, A. (2010). Research of influence of support resistance of the stope in the immediate roof condition. New Techniques and Technologies in Mining, 127-130. https://doi.org/10.1201/b11329-21

4. Pivnyak, G.G., \& Shashenko, O.M. (2015). Innovations and safety for coal mines in Ukraine. Naukovyi Visnyk Natsionalnoho Hirnychoho Universytetu, (6), 118-121.

5. Golinko, V.I., Yavorskiy, A.V., Lebedev, Ya.Ya., \& Yavorskaya, Ye.A. (2014). Estimation of frictional sparking effect on firedamp inflammation during fragmentation of gas-saturated rock massif. Naukovyi Visnyk Natsionalnoho Hirnychoho Universytetu, (6), 31-37.

6. Dryzhenko, A., Shustov, A., \& Moldabayev, S. (2017). Justification of parameters of building inclined trenches using belt conveyors. 17th International Multidisciplinary Scientific GeoConference SGEM 2017, 471-478. DOI:10.5593/sgem2017/13/S03.060

7. Falshtynskyi, V.S., Dychkovskyi, R.O., Saik, P.B., Lozynskyi, V.G., \& E. Cáceres Cabana. (2017). Formation of thermal fields by the energy-chemical complex of coal gasification. Naukovyi Visnyk Natsionalnoho Hirnychoho Universytetu, (5), 36-42.

8. Lozynskyi, V., Dychkovskyi, R., Saik, P., Falshtynskyi, V. (2018). Coal Seam Gasification in Faulting Zones (Heat and Mass Balance Study). Solid State Phenomena, (277), 66-79. https://doi.org/10.4028/www.scientific.net/SSP.277.66

9. Bondarenko, V., Tabachenko, M., \& Wachowicz, J. (2010). Possibility of production complex of sufficient gasses in Ukraine. New Techniques and Technologies in Mining, 113-119.

10. Golinko, V.I., Cheberiachko, S.I., Yavors'ka, O.O., \& Tykhonenko, V.V. (2017). Assessment of protection level of dust respirators at coal mines. Naukovyi Visnyk Natsionalnoho Hirnychoho Universytetu, (3), 102-107.

11. Cheberiachko, S.I., Yavorska, O.O., \& Morozova, T.I. (2013). Study of mechanical half-mask pressure along obturation bar. Technical and Geoinformational Systems in Mining, 317-323.

12. Newnum, J.D. (2010) The effect sofrelative humidity on respirator performance. Master's thesis, University of Iowa, http://ir.uiowa.edu/etd/861

13. Holinko, V., Cheberiachko, S., Yavorska, O., \& Radchuk, D. (2016). Issledovanie zashchitnykh svoystv respiratorov-polumasok, ispol'zuemykh shakhterami. Min. Miner. Depos., 10(4), 29-36.

14. Fabbro, L.D., Brun, P., Laborde, J.C., Lacan, J., Renoux, A., \& Ricciardi L. (2012). Contribution to the modelling of industrial pleated filters by solid particles. American Journal of Environmental Science, 8(4), 385-395.

15. Tikhonov, M.M., Parmon, V.V., Boinichev, O.N., \& Ryabtsev, V.N. (2015). Assessment of protective efficiency of respiratory protection devices to provide safe operation in the zone of radioactive contamination. Vestnik Komandno-inzhenernogo instituta MChS Respubliki Belarus', $1(21), 58-67$.

16. Haruta, H., Honda, T., \& Eninger, R.M. (2009). Experimental and theoretical investigation of the performance of N95 respirator filters against ultrafine aerosol particles tested at constant and cyclic flows. Journal Int. Soc. Respir. Prot., (25), 75-88.

17. Feng, Z., Long, Z., \& Chen, Q. (2014). Assessment of Various CFD Models for Predicting Airflow and Pressure Drop Through Pleated Filter System. Build. Environ., (75), 132-141. 